\title{
Pengaruh Lama Perendaman Dan Konsentrasi Kalium Nitrat (KNO3) Terhadap Pematahan Masa Dormansi Biji Kopi Robusta (Coffea canephora)
}

\author{
The Effect of Soaking Time and Consentration of Potassium Nitrate $\left(\mathrm{KNO}_{3}\right)$ on \\ Dormancy Breaking of Robusta (Coffea canephora)
}

\author{
Alam Wijaya $^{1)}$, Dwi Fitriani ${ }^{2)}$, Rita Hayati ${ }^{2)}$ \\ 1). Mahasiswa Prodi Agroteknologi Fakultas Pertanian Dan Peterakan \\ 2). Dosen Prodi Agroteknologi Fakultas Pertanian Dan Peterakan
}

\begin{abstract}
ABSTRAK
Pembibitan kopi sering dihadapkan dengan masa dormansi biji kopi yang disebabkan oleh kulit ari biji kopi yang keras. Kalium nitrat $\left(\mathrm{KNO}_{3}\right)$ dapat melunakkan kulit biji dan mempermudah air masuk ke dalam biji, sehingga mempercepat proses metabolisme. Penelitian ini bertujuan untuk mengetahui pengaruh lama perendaman dan konsentrasi kalium nitrat $\left(\mathrm{KNO}_{3}\right)$ terhadap pematahan masa dormansi biji kopi robusta. Rancangan penelitian ini menggunakan Rancangan Acak Lengkap Faktorial (RAL-F), dengan faktor pertama lama perendaman (L) yang terdiri atas tiga taraf meliputi 12 jam (L1), 24 jam (L2), 36 jam (L3) dan faktor kedua konsentrasi $\mathrm{KNO}_{3}(\mathrm{~K})$ yang terdiri atas 4 taraf meliputi $0 \%(\mathrm{~K} 0), 0.5 \%(\mathrm{~K} 1), 1.0 \%$ (K2) dan $1.5 \%$ (K3). Faktor lama perendaman berpengaruh nyata terhadap kecambah normal (biji), kecambah abnormal (biji), daya berkecambah (\%), potensi tumbuh maksimum (\%), waktu berkecambah (hr). Faktor konsentrasi $\mathrm{KNO}_{3}$ berpengaruh nyata terhadap kecambah normal (biji), kecambah abnormal (biji), daya berkecambah (\%), potensi tumbuh maksimum (\%) dan waktu berkecambah (hr). Hasil penelitian ini menunjukkan bahwa terdapat interaksi antara lama perendaman $(\mathrm{L})$ dan konsentrasi kalium nitrat $(\mathrm{K})$ terhadap efektivitas pematahan masa dormansi biji kopi robusta.
\end{abstract}

Kata kunci : dormansi, lama perendaman, konsentrasi, kalium nitrat, robusta.

\section{ABSTRACT}

Coffee nurseries are often faced with a period of coffee bean dormancy caused by the hard coffee bean husks. Potassium nitrate ( $\left.\mathrm{KNO}_{3}\right)$ can soften the seed coat and make it easier for water to enter the seeds, thereby speeding up the metabolic process. This research aims to determine the effect of immersion time and concentration of potassium nitrate $\left(\mathrm{KNO}_{3}\right)$ on breaking the dormancy period of robusta beans. The design of this research used a Factorial Completely Randomized Design, with the first factor immersion time $(L)$ which consisted of three levels including 12 hours (L1), 24 hours (L2), 36 hours (L3) and the second factor was the concentration of $\mathrm{KNO}_{3}(\mathrm{~K})$ which consists of 4 levels including 0\% (KO), 0.5\% (K1), 1.0\% (K2) and 1.5\% (K3).

Soaking time had a significant effect on the average germination day (day), normal germination (seeds), abnormal sprouts (seeds), germination (\%), maximum growth potential (\%). The $\mathrm{KNO}_{3}$ concentration factor had a significant effect on the average germination day (day), normal germination (seeds), abnormal sprouts (seeds), germination (\%), maximum growth potential (\%). The results of this research indicate that there is an interaction between the soaking time $(L)$ and the concentration of potassium nitrate $(K)$ on the effectiveness of breaking the dormancy period of robusta.

Keywords: dormancy, immersion time, concentration, potassium nitrate, robusta. 


\section{BAB I \\ PENDAHULUAN}

Kopi merupakan komoditas perkebunan yang memegang peranan penting dalam perekonomian Indonesia. Komoditas ini diperkirakan menjadi sumber pendapatan utama tidak kurang dari 1,84 juta keluarga yang sebagian besar mendiami kawasan pedesaan di wilayah-wilayah terpencil. Selain itu, lebih kurang 1 juta keluarga mengandalkan pendapatannya dari industri hilir dan perdagangan kopi. Kopi merupakan komoditas ekspor penting bagi Indonesia yang mampu menyumbang devisa yang cukup besar (Hadi, Hudoro, H.B., Novariyanthy, M., Tanjung, I. I., Mutowil, Soedjana, M. I., Mulyono, 2014).

Pengembangan komoditas kopi robusta di Kepahiang masih cukup terbuka, baik melalui program perluasan, maupun intensifikasi untuk meningkatkan produktivitas. Salah satu upaya untuk meningkatkan kualitas dan kuantitas produksi kopi di Kepahiang adalah dengan menggunakan bibit kopi yang berkualitas. Ketersediaan bibit dapat dilakukan dengan cara perbanyakan tanaman secara generatif (dengan biji).

Proses pembibitan kopi sering kali dihadapkan pada kendala biji yang mengalami masa dormansi. Menurut Saputra, D., Zuhry, E. dan Yoseva, S. (2016), dormansi merupakan suatu kondisi di mana benih tidak berkecambah walaupun berada dikondisi optimum untuk perkecambahannya. Benih yang terhambat dalam berkecambah pada umumnya disebabkan karena adanya hambatan pada kulit benih yang keras.

Perlakuan pematahan dormansi dapat dilakukan dengan mekanis (stratifikasi dan pengguntingan kulit) dan kimiawi seperti asam sulfat, potassium nitrat serta hormon pertumbuhan seperti giberelin untuk memacu perkecambahan biji (Kartasapoetra, 2003 dalam Astari R.P., Rosmayati dan Bayu E.S., 2013). Menurut Sutopo (1985) dalam Nengsih (2017), perlakuan menggunakan bahan kimia bertujuan agar kulit biji lebih mudah dimasuki air pada waktu proses imbibisi. Salah satu bahan kimia yang dapat digunakan adalah larutan $\mathrm{KNO}_{3}$.

Penelitian yang berkaitan dengan penggunaan $\mathrm{KNO}_{3}$ dilakukan oleh Nengsih (2017), perlakuan terbaik untuk uji pematahan dormansi benih kopi liberika adalah perendaman dalam larutan $\mathrm{KNO}_{3}$ dengan konsentrasi 0,5\% selama 24 jam yang menunjukkan persentase daya berkecambah sebesar $58,33 \%$ dan tinggi kecambah mencapai 7,78 cm. Menurut Jeminar (1984) dalam Saputra dkk. (2016), konsentrasi $\mathrm{KNO}_{3} \quad 0,3 \%$ dengan lama perendaman 24 jam

biji kopi Arabika mencapai 65,33\%. Menurut Pertiwi, N. M., Tahir, M., Same, M. (2015), perlakuan waktu perendaman terbaik pada perendaman selama 24 jam dapat meningkatkan persentase benih berkecambah, panjang hipokotil, dan bobot berangkasan benih kopi robusta.

Berdasarkan uraian di atas, untuk mematahkan masa dormansi biji pada tanaman kopi robusta (Coffea canephora) maka perlu dilakukan penelitian tentang "Pengaruh Lama Perendaman Dan Konsentrasi Larutan Kalium Nitrat $\left(\mathrm{KNO}_{3}\right)$ Terhadap Pematahan Masa Dormansi Biji Kopi Robusta (Coffea canephora)".

\section{BAB II \\ METODOLOGI PENELITIAN}

\subsection{Tempat dan Waktu Penelitian}

Penelitian ini telah dilaksanakan pada bulan Juni 2019 sampai dengan bulan September 2019 dan bertempat di Kelurahan Dusun Kepahiang Kecamatan Kepahiang Kabupaten 
Kepahiang dengan ketinggian $528 \mathrm{~m}$ di atas permukaan laut

\subsection{Alat dan Bahan}

Alat yang digunakan adalah alat tulis, bambu, cangkul, cangkir plastik, ember, gelas beaker $1000 \mathrm{ml}$, gergaji, jerigen 1 liter, kamera, kertas label, paranet, ph meter analog, pisau, sprayer, tali plastik, timbangan analitik dan timer. Sedangkan bahan yang digunakan adalah air, biji kopi robusta (Coffea canephora) lokal Kepahiang, kalium nitrat $\left(\mathrm{KNO}_{3}\right)$, kapur pertanian (dolomit), media perkecambahan berupa polybag yang terdiri dari tanah lapisan atas (top soil) dengan $\mathrm{pH}$ berkisar 5.6.

Tanah lapisan atas (top soil) diberikan pupuk dasar anorganik (NPK dengan konsentrasi 1,5\% sebanyak 100 $\mathrm{ml} /$ polybag ), serta pupuk tambahan yang diberikan 2 minggu sekali (urea dengan konsentrasi 1\% sebanyak 100 $\mathrm{ml} /$ polybag pada penyiraman pagi, TSP dan KCL dengan konsentrasi masingmasing 2\% sebanyak $100 \mathrm{ml} /$ polybag pada penyiraman sore).

\subsection{Rancangan Penelitian}

Rancangan penelitian yang digunakan adalah Rancangan Acak Lengkap-Faktorial (RAL-F) dua faktor dangan faktor pertama yaitu lama perendaman (L) sedangkan faktor kedua yaitu konsentrasi kalium nitrat $\left(\mathrm{KNO}_{3}\right)$ (K). Faktor lama perendaman (L), terdiri atas tiga taraf yaitu $\mathrm{L}_{1}=12 \mathrm{jam}$, $\mathrm{L}_{2}=24 \mathrm{jam}, \mathrm{L}_{3}=36 \mathrm{jam}$

Faktor Konsentrasi Kalium Nitrat $\left(\mathrm{KNO}_{3}\right)(\mathrm{K})$, terdiri atas empat taraf yaitu : $\mathrm{K}_{0}=0 \%, \mathrm{~K}_{1}=0.5 \%, \mathrm{~K}_{2}=1.0 \%$, $\mathrm{K}_{3}=1.5 \%$

\subsection{Peubah Yang Diamati}

Adapun peubah yang diamati dalam penelitian ini antara lain yaitu kecambah normal (biji), kecambah abnormal (biji), daya berkecambah (\%), potensi tumbuh maksimum (\%), waktu berkecambah (hr), panjang akar $(\mathrm{cm})$, tinggi tanaman $(\mathrm{cm})$, jumlah daun (helai), berat akar (gram), berat basah tanaman (gram) dan berat kering tanaman (gram).

\section{BAB III \\ HASIL DAN PEMBAHASAN}

\subsection{HASIL}

Hasil analisis keragaman untuk masing-masing faktor dan interaksinya terhadap semua peubah yang diamati dapat dilihat pada tabel 1 .

Tabel 1. Kecambah Normal/KN (biji), Kecambah Abnormal/KAb (biji), Daya Berkecambah/DB (\%), Potensi Tumbuh Maksimum/PTM (\%), Waktu Berkecambah/WB (hr), Panjang Akar/PA (cm), Tinggi Tanaman/TT (cm), Jumlah Daun/JD (helai), Berat Akar/BA (gr), Berat Basah Tanaman/BBT (gr) dan Berat Kering Tanaman/BKT(gr)

\begin{tabular}{lrrrr}
\hline \multirow{2}{*}{ Peubah Yang di Amati } & \multicolumn{3}{c}{ F hitung } & \multirow{2}{*}{ KK (\%) } \\
\cline { 2 - 4 } & \multicolumn{1}{c}{ L } & K & L. K & \\
\hline Kecambah Normal (KN) & $72.93^{* *}$ & $21.23^{* *}$ & $4.08^{* *}$ & $7.72 \%$ \\
Kecambah Abnormal (KAb) & $9.01^{* *}$ & $32.37^{* *}$ & $3.58^{*}$ & $12.75 \%$ \\
Daya Berkecambah (DB) & $72.93^{* *}$ & $21.23^{* *}$ & $4.08^{* *}$ & $7.72 \%$ \\
Potensi Tumbuh Maksimum (PTM) & $79.59^{* *}$ & $23.93^{* *}$ & $1.89^{\text {tn }}$ & $7.92 \%$ \\
Waktu Berkecambah(WB) & $175.44^{* *}$ & $66.84^{* *}$ & $3.82^{* *}$ & $2.17 \%$
\end{tabular}

Keterangan :
L : Lama Perendaman
$\mathrm{K} \quad$ : Konsentrasi Kalium Nitrat $\left(\mathrm{KNO}_{3}\right)$
L . : Interaksi
$\mathrm{K}$ 


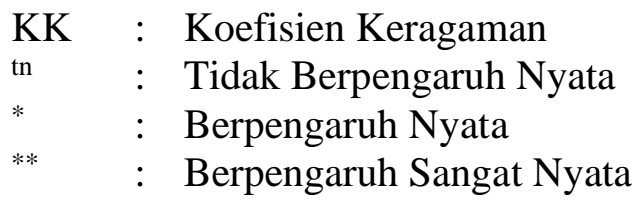

\subsection{PEMBAHASAN}

Pengaruh masing-masing faktor terhadap kecambah normal dapat dilihat pada diagram garis sebagai berikut:

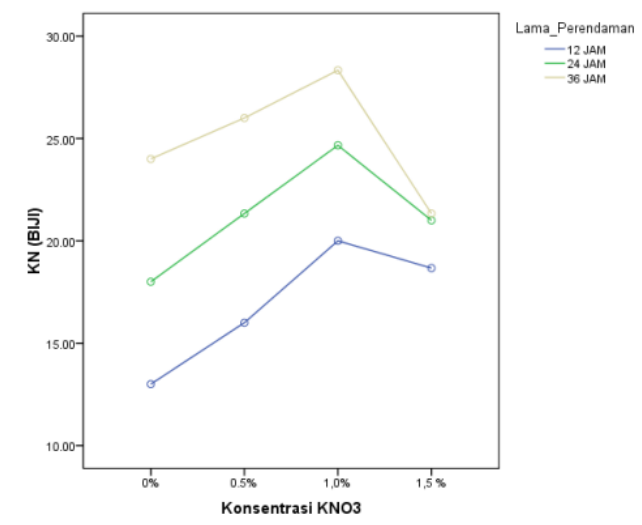

Gambar Pengaruh faktor lama 1 perendaman dan faktor konsentrasi $\quad \mathrm{KNO}_{3}$ terhadap kecambah normal (biji)

Berdasarkan gambar 1 dapat disimpulkan bahwa untuk mendapatkan jumlah kecambah normal yang tinggi dapat melakukan peningkatan jumlah konsentrasi $\mathrm{KNO}_{3}$ dan peningkatan lama perendaman. Namun pada konsentrasi $\mathrm{KNO}_{3} \quad 1,5 \%$ jumlah kecambah normal menurun. Perlakuan lama perendaman 24 jam dan konsentrasi $\mathrm{KNO}_{3} \quad 1.5 \%$ dan lama perendaman 36 jam dan konsentrasi $\mathrm{KNO}_{3} \quad 1.5 \%$ tidak berbeda nyata dengan jumlah kecambah normal yang lebih sedikit dibandingkan konsentrasi $\mathrm{KNO}_{3} 1.0 \%$.

Jumlah kecambah normal tertinggi terdapat pada lama perendaman 24 jam dan konsentrasi KNO3 $1.0 \%$ yaitu sekitar 28.33 biji dari 50 biji sampel yang dikecambahkan. Hal ini dikarenakan bahwa perendaman dengan larutan $\mathrm{KNO}_{3}$ dapat melunakkan kulit ari biji kopi sehingga biji akan cepat berkecambah dan dapat meningkatkan daya kecambah. Menurut Marzuki (2007), semakin lama perendaman diduga dapat menyebabkan kulit biji lebih permeabel terhadap oksigen, sehingga memungkinkan oksigen masuk ke dalam biji sampai mencapai level yang cukup tinggi. Akibatnya benih dapat berimbibisi.

Pengaruh masing-masing faktor terhadap kecambah abnormal dapat dilihat pada diagram garis sebagai berikut:

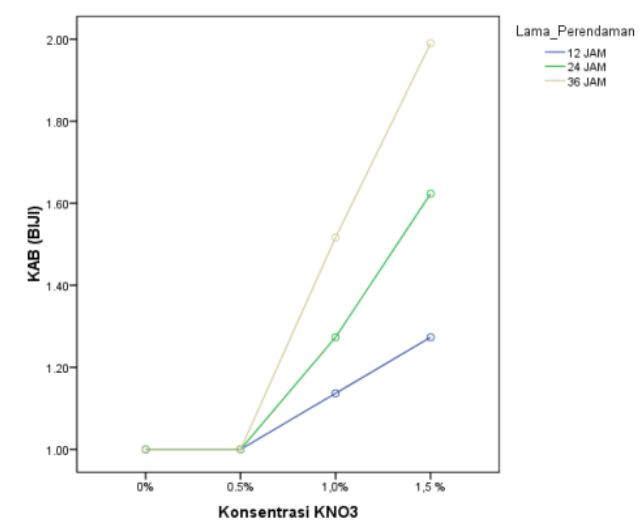

Gambar Pengaruh faktor lama 2 perendaman dan faktor konsentrasi $\mathrm{KNO}_{3}$ terhadap kecambah abnormal (biji)

Berdasarkan gambar 2 dapat disimpulkan bahwa pada peubah kecambah abnormal dapat dilihat bahwa faktor konsentrasi $\mathrm{KNO}_{3}(\mathrm{~K})$ dalam taraf $\mathrm{K} 0\left(\mathrm{KNO}_{3} 0 \%\right)$ dan $\mathrm{K} 1\left(\mathrm{KNO}_{3}\right.$ $0.5 \%$ ) tidak menghasilkan kecambah abnormal. Kecambah abnormal muncul pada taraf $\mathrm{K} 2\left(\mathrm{KNO}_{3} 1.0 \%\right)$ dan $\mathrm{K} 3$ $\left(\mathrm{KNO}_{3} \quad 1.5 \%\right)$. Jumlah kecambah abnormal meningkat seiring dengan meningkatnya taraf lama perendaman (L). Menurut Sela (2018) $\mathrm{KNO}_{3}$ yang 
terlalu tinggi akan memberikan respon negatif pada perkecambahan benih karena konsentrasi $\mathrm{KNO}_{3}$ yang terlalu pekat akan merusak jaringan embrio sehingga ada benih yang tidak tumbuh pada akhirnya menurunkan persentase perkecambahan.

Hasil uji lanjut DMRT (Duncan's Multiple Range Test) daya berkecambah dapat dilihat pada Tabel 2 .

Tabel Daya berkecambah berdasarkan lama perendaman dan pengaruh 2. konsentrasi $\mathrm{KNO}_{3}(\%)$

\begin{tabular}{|c|c|c|c|c|c|}
\hline \multirow{2}{*}{$\begin{array}{c}\text { Lama } \\
\text { Perendaman }\end{array}$} & \multicolumn{4}{|c|}{ Konsentrasi $\mathrm{KNO}_{3}$} & \multirow{2}{*}{$\begin{array}{c}\text { Pengaruh Lama } \\
\text { Perendaman }\end{array}$} \\
\hline & $\mathrm{KO}$ & $\mathrm{K} 1$ & $\mathrm{~K} 2$ & $\mathrm{~K} 3$ & \\
\hline L1 & $26.00 \mathrm{a}$ & $\begin{array}{c}32.00 \\
b\end{array}$ & $\begin{array}{c}40.00 \\
\mathrm{~cd}\end{array}$ & $\begin{array}{c}37.33 \\
\text { bcd }\end{array}$ & $33.83 \mathrm{~A}$ \\
\hline L2 & $36.00 \mathrm{bc}$ & $\begin{array}{c}42.67 \\
\text { de }\end{array}$ & $49.33 \mathrm{f}$ & $42.00 \mathrm{~d}$ & $42.50 \mathrm{~B}$ \\
\hline L3 & $48.00 \mathrm{ef}$ & $\begin{array}{c}52.00 \\
\text { fg }\end{array}$ & $\begin{array}{c}56.67 \\
\mathrm{~g}\end{array}$ & $42.67 \mathrm{de}$ & $49.83 \mathrm{C}$ \\
\hline $\begin{array}{c}\text { Pengaruh } \\
\text { Konsentrasi } \\
\mathrm{KNO}_{3} \\
\end{array}$ & $36.67 \mathrm{~A}$ & $\begin{array}{c}42.22 \\
\mathrm{C}\end{array}$ & $\begin{array}{c}48.67 \\
\mathrm{D}\end{array}$ & $40.67 \mathrm{~B}$ & \\
\hline
\end{tabular}

Keteranga Angka-angka yang diikuti oleh huruf pada baris dan kolom yang

$\mathrm{n}$ : sama tidak berbeda nyata dengan uji DMRT pada taraf $5 \%$.

Berdasarkan hasil uji lanjut Pada pengamatan daya DMRT (Duncan's Multiple Range Test) berkecambah dengan faktor lama bahwa perlakuan lama perendaman L1 perendaman selama 36 jam memberikan berbeda nyata dengan perlakuan L2 dan nilai tertinggi terhadap daya L3. Perlakuan L2 berbeda nyata dengan berkecambah yaitu sebesar $49.8 \%$. perlakuan L3. Perlakuan konsentrasi Faktor konsentrasi $\mathrm{KNO}_{3} \quad 1,0 \%$ $\mathrm{KNO}_{3} \quad \mathrm{~K} 0$ berbeda nyata dengan memberikan nilai tertinggi terhadap perlakuan K1, K2 dan K3. Namun perlakuan konsentrasi $\mathrm{KNO}_{3} \mathrm{~K} 1$ dan $\mathrm{K} 3$ tidak berbeda nyata. daya berkecambah yaitu $48.7 \%$.

Hasil uji lanjut DMRT (Duncan's Multiple Range Test) potensi tumbuh maksimum dapat dilihat pada Tabel 3.

Tabel Potensi Tumbuh Maksimum berdasarkan lama perendaman dan $3 . \quad$ pengaruh konsentrasi $\mathrm{KNO}_{3}(\%)$

\begin{tabular}{cccccc}
\hline \multirow{2}{*}{ Lama Perendaman } & \multicolumn{4}{c}{ Konsentrasi $\mathrm{KNO}_{3}$} & Pengaruh Lama \\
\cline { 2 - 5 } & KO & K1 & K2 & K3 & Perendaman \\
\hline L1 & 26.00 & 32.00 & 40.67 & 38.67 & $34.33 \mathrm{~A}$ \\
L2 & 36.00 & 42.67 & 50.67 & 45.33 & $43.67 \mathrm{~B}$ \\
L3 & 48.00 & 52.00 & 59.33 & 48.67 & $52.00 \mathrm{C}$ \\
\hline Pengaruh & \multirow{2}{*}{$36.67 \mathrm{~A}$} & $42.22 \mathrm{~B}$ & $50.22 \mathrm{C}$ & $44.22 \mathrm{~B}$ & \\
Konsentrasi $\mathrm{KNO}_{3}$ & & & &
\end{tabular}

Keterangan : Angka-angka yang diikuti oleh huruf pada baris dan kolom yang sama tidak berbeda nyata dengan uji DMRT pada taraf $5 \%$.

Berdasarkan hasil uji lanjut berbeda nyata dengan perlakuan K1, K2 DMRT (Duncan's Multiple Range Test) bahwa perlakuan lama perendaman L1 berbeda nyata dengan perlakuan L2 dan L3. Perlakuan konsentrasi $\mathrm{KNO}_{3} \mathrm{KO}$ dan K3. Pada pengamatan potensi tumbuh maksimum dengan lama perendaman selama 36 jam memberikan nilai tertinggi terhadap potensi tumbuh 
maksimum yaitu sebesar 52\%. Perlakuan konsentrasi $\mathrm{KNO}_{3} \quad 1,0 \%$ memberikan nilai tertinggi terhadap potensi tumbuh maksimum yaitu $50 \%$.

Pengaruh masing-masing faktor terhadap waktu berkecambah dapat dilihat pada diagram garis sebagai berikut:

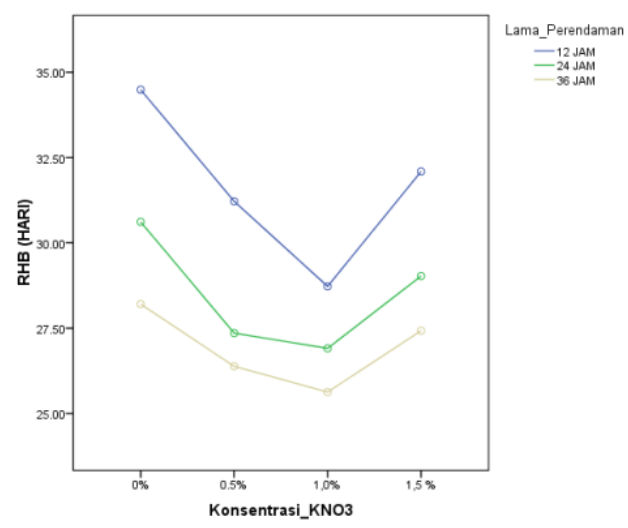

Gambar Pengaruh faktor lama 3. perendaman dan faktor konsentrasi $\mathrm{KNO}_{3}$ terhadap waktu berkecambah

Berdasarkan gambar 3 dapat disimpulkan bahwa semakin lama perendaman maka kecil nilai rerata hari berkecambah. Semakin besar konsentrasi $\mathrm{KNO}_{3}$ maka akan semakin kecil nilai rerata hari berkecambah, tetapi tidak berlaku pada konsentrasi $\mathrm{KNO}_{3} \quad 1.5 \% \quad(\mathrm{~K} 3)$ semua yang menunjukkan adanya peningkatan nilai rerata hari berkecambah dari taraf sebelumnya (K2).

Waktu Berkecambah menunjukkan nilai terendah (paling cepat berkecambah) yaitu berada dalam kisaran 25,63 hari (L3K2) sedangkan nilai tertinggi (paling lama berkecambah) berada dalam kisaran 34,48 hari (L1K0). Berdasarkan data analisis ragam waktu berkecambah diduga bahwa faktor lama perendaman dan faktor konsentrasi $\mathrm{KNO}_{3}$ terbukti dapat mematahkan masa dormansi biji kopi robusta. Hal ini dibuktikan dengan turunnya nilai rerata hari berkecambah seiring dengan meningkatnya lama perendaman dan meningkatnya konsentrasi $\mathrm{KNO}_{3}$ (kecuali K3). Menurut Hamidah (2013), efektivitas pematahan dormansi menggunakan $\mathrm{KNO}_{3}$ tergantung dengan lama perendaman dan konsentrasi $\mathrm{KNO}_{3}$. Semakin lama perendaman dan semakin tinggi konsentrasi $\mathrm{KNO}_{3}$ maka intensitas dormansi semakin rendah.

\section{BAB IV KESIMPULAN}

\subsection{Kesimpulan}

Berdasarkan hasil dan pembahasan tentang Pengaruh Lama Perendaman Dan Konsentrasi Kalium Nitrat $\left(\mathrm{KNO}_{3}\right)$ Terhadap Pematahan Masa Dormansi Biji Kopi Robusta dapat disimpulkan bahwa:

1. Perlakuan lama perendaman (L) berpengaruh nyata terhadap kecambah normal (biji), kecambah abnormal (biji), daya berkecambah (\%), potensi tumbuh maksimum (\%), waktu berkecambah (hr),

2. Perlakuan konsentrasi kalium nitrat (K) berpengaruh nyata terhadap kecambah normal (biji), kecambah abnormal (biji), daya berkecambah $(\%)$, potensi tumbuh maksimum (\%), waktu berkecambah (hr),

3. Terdapat interaksi antara lama perendaman (L) dan konsentrasi kalium nitrat (K) terhadap kecambah normal (biji), kecambah abnormal (biji), daya berkecambah (\%), waktu berkecambah (hr),

\subsection{Saran}

Jika ingin mempersingkat lama perendaman untuk mempercepat perkecambahan biji kopi, maka perlu meningkatkan konsentrasi $\mathrm{KNO}_{3}$ yang digunakan. Namun hal ini tidak berlaku pada konsentrasi $\mathrm{KNO}_{3} 1.5 \%$. 


\section{DAFTAR PUSTAKA}

Arief, M.C.W., Tarigan, M., Saragih, R., dan Rahmadani, F. 2011. Panduan Sekolah Lapangan Budidaya Kopi Konservasi. Conservation International Indonesia. Jakarta.

Astari R.P., Rosmayati dan Bayu E.S. 2013. Pengaruh Pematahan Dormansi Secara Fisik Dan Kimia Terhadap Kemampuan Berkecambah Benih Mucuna (Mucuna bracteata D.C). Jurnal Online Agroekoteknologi . ISSN No. 2337- 6597. Vol.2, No.2 : 803 - 812, Maret 2014

Direktorat Jendral Perkebunan. 2015. Statistik Perkebunan Indonesia. Sekretariat Direktorat Jenderal Perkebunan . Jakarta

Fadhilah, S. 2018. Pengujian Daya Berkecambah. Balai Besar Pengembangan Pengujian Mutu Benih Tanaman Pangan dan Hortikultura. Bogor

Hadi, Hudoro, H.B., Novariyanthy, M., Tanjung, I. I., Mutowil, Soedjana, M. I., Mulyono, I. 2014. Pedoman Teknis Budidaya Kopi Yang Baik (Good Agriculture Practices /Gap On Coffee). Kementerian Pertanian Direktorat Jendral Perkebunan. Jakarta

Hamidah. 2013. Perlakuan Lama Perendaman dan Konsentrasi $\mathrm{KNO}_{3}$ Terhadap Pematahan Dormansi Benih Padi (Oryza sativa L.) Varietas Ciherang. Fakultas Pertanian Universitas Syiah Kuala. Banda Aceh

Hartawan, Rudi. 2013. Skarifikasi Dan $\mathrm{KNO}_{3}$ Mematahkan Dormansi Serta Meningkatkan Viabilitas Dan Vigor Benih Aren (Arenga Pinnata Merr.) Fakultas Pertanian Universitas Batanghari. Jambi
Jurnal Media Pertanian Vol. 1 No. 1 Tahun 2016 Hal. 1 - 10

Herdiyantoro, D. 2013. Rancangan Faktorial Rancangan Acak Kelompok Rancangan Acak Kelompok. Fakultas Pertanian Universitas Padjadjaran. Bandung.

ISTA. (2010). International Rules for Seed Testing Edition 2010. International Seed Testing Association. Zurich Switzerland

Marzuki, I. 2007. Pengaruh Penambahan Larutan Kalium Nitrat (KNO3) Terhadap Pematahan Dormansi Benih Padi (Oryza sativa L.) Varietas Sintanur. Akademi Analis Kimia Yapika. Makassar

Murniati dan Zuhry, E. 2002. Peranan Giberelin Terhadap Perkecambahan Benih Kopi Robusta Tanpa Kulit. Jurnal Sagu 1: $1-5$.

Najiyati, S dan Danarti. 2012. Kopi, Budidaya dan Penanganan Lepas Panen. PT. Penebar Swadaya. Jakarta.

Nasir, G. 2015. Pedoman Teknis Pengembangan Tanaman Kopi Berkelanjutan Tahun 2015. Direktorat Jenderal Perkebunan Kementerian Pertanian. Jakarta

Nengsih, Yulistiati. 2017. Penggunaan Larutan Kimia Dalam Pematahan Dormansi Benih Kopi Liberika. Universitas Batanghari. Jambi

Nuraeni dan Maemunah. 2003. Peran Air dan $\mathrm{KNO}_{3}$ dalam Pemecahan Dormansi Benih dan Pertumbuhan Bibit Kemiri (Aleurites moluccana W). Jurnal Ilmu- Ilmu Pertanian Agroland Vol. 10 No. 3 September 2003

Pertiwi, N. M., Tahir, M., Same, M. 2015. Respons Pertumbuhan Benih Kopi Robusta terhadap 
Waktu Perendaman dan Konsentrasi Giberelin (GA3). Jurusan Budidaya Tanaman Perkebunan, Politeknik Negeri Lampung. Bandar Lampung.

Prastowo, B., Karmawati, E., Rubijo, Siswanto, Indrawanto, C., Munarso, S.J. 2010. Budidaya dan Pasca Panen Kopi. Pusat Penelitian dan Pengembangan Perkebunan. Bogor

Rahardjo, Pudji. 2012. Panduan Budidaya dan Pengolahan Kopi Arabika Dan Robusta. Penebar Swadaya. Jakarta

Rahardjo, Puji. 2017. Berkebun Kopi. Penebar Swadaya. Jakarta Timur

Rangkuti, A.L., 2000. Pematahan dormansi dengan H2SO4 pada perkecambahan benih aren (Arenga pinnata (W) Merr). Fakultas Pertanian Universitas Riau, Pekanbaru. (Tidak dipublikasikan).

Risnandar, C. dan Fahmi, A. 2018. Kopi Robusta.

https://jurnalbumi.com/knol/ kopirobusta/ diakses pada tanggal 21 Desember 2018 pukul 17.15 WIB.

Sagala, Y., Hanafiah, A. S., \& Razali. (2013). Peranan mikoriza terhadap pertumbuhan, serapan $P$ dan Cd tanaman sawi (Brassica juncea L.) serta kadar $P$ dan $C d$ Andisol yang diberi pupuk fosfat alam. Fakultas Pertanian USU. Medan. Jurnal Online Agroekoteknologi, 2(1), 487-500. Retrieved from https://jurnal.usu.ac.id/index.php/ agroekoteknologi/article/view/586 6/ 2589

Sajad, S. 1993. Dari Benih Kepada Benih. PT Gramedia Widiasarana Indonesia. Jakarta

Saleh, M.S. Adelina, E. Murniati, E dan Budiarti, T. 2008. Pengaruh Skarifikasi dan Media Tumbuh
Terhadap Viabilitas Benih dan Vigor Kecambah Aren. Jurnal Agroland 15 (3) : 182-190.

Saputra, D., Zuhry, E. dan Yoseva, S. 2016. Pematahan Dormansi Benih Kelapa Sawit (Elaeis guineensis Jacq.) Dengan Berbagai Konsentrasi Kalium Nitrat (KNO3) Dan Pengaruhnya Terhadap Pertumbuhan Bibit Pada Tahap Pre Nursery. Program Studi Agroteknologi Jurusan Agroteknologi Fakultas Pertanian Universitas Riau. Riau. Jom Faperta Vol.4 No 2: Oktober 2017.

Sela. 2018. Pengaruh $\mathrm{KNO}_{3}$ Dengan Konsentrasi Berbeda Terhadap Perkecambahan Benih Pinang (Areca katechu L.) Yang Telah Diskarifikasi Mekanis. Universitas Jambi. Jambi

Sihotang, A.R. 1999. Pengaruh Lama Perendaman dan Konsentrasi Kalium Nitrat $\left(\mathrm{KNO}_{3}\right)$ terhadap Perkecambahan Benih Kemiri. Fakultas Pertanian USU. Medan

Silomba, D. Arruan. 2006. Pengaruh Lama Perendaman dan Pemanasan Terhadap Viabilitas Benih Kelapa Sawit (Elaeis guineensis Jaqc.). Institut Pertanian Bogor. Bogor

Simatupang, B., Effendi, R., Kurniaty, R. 2014. Teknik Pematahan Dormansi Benih Ganitri (Elaeocarpus ganitrus Roxb). Balai Penelitian Teknologi Perbenihan Tanaman Hutan. Bogor

Supiniati. 2015. Pengaruh Lama Perendaman Dan Konsentrasi $\mathrm{KNO}_{3}$ Terhadap Viabilitas Benih Lengkeng (Dimocarpus longan lour). Universitas Teuku Umar. Aceh

Sutopo, L. 2002. Teknologi Benih. Raja Grafindo Persada. Jakarta 
Triyanti, D. R. 2016. Outlook Kopi Komoditas Pertanian Subsektor Perkebunan. Pusat Data dan Sistem Informasi Pertanian Sekretariat Jenderal Kementerian Pertanian. Jakarta

Ulfa, S.W. 2010. Dormansi, Penuaan dan Mati. Online. http://bilogimaterial.

Blogspot.com/2010/09/dormansipenuaan-dan-mati.html? $\mathrm{m}=1$

Viarini, S, A. 2007. Perlakuan $\mathrm{KNO}_{3}$ dan Suhu Inkubasi Pengaruhnya Terhadap Pematahan Dormansi Benih Kelapa Sawit (Elaeis guineensis Jacqvar Tenera). Fakultas Pertanian. Universitas Gadjah Mada. Yoyakarta

Widhityarini D., Suyadi M.W.,dan Aziz P. 2011. Pematahn dormansi benih tanjung (Mimusops elengi L.) dengan skarifikasi dan perendaman kalium nitrat. Fakultas Pertanian. Universitas Gajah Mada. Yogyakarta. 